\title{
MULHERES EM SITUAÇÃO DE VIOLÊNCIA E O ÂMBITO PÚBLICO-LABORAL COMO FORMA DE OPRESSÃO
}

\author{
LAS MUJERES EN SITUACIÓN DE VIOLENCIA Y EL ÁMBITO PÚBLICO-LABORAL \\ COMO FORMA DE OPRESIÓN
}

Lídia PiuccoUgioni ${ }^{1}, 3$; Ariane Maggi Coelho Schwanck $2,3{ }^{*}$

Erro! Fonte de referência não encontrada.

O presente trabalho se propõe a fazer uma análise da violência doméstica e das lutas das mulheres na prevenção e no combate à violência,ao longo dos anos, tal análise denota uma série de fatores, e entre eles, pretende-se estudar a violência patrimonial, por exemplo, elencada no artigo $7^{\circ}$, inciso IVda Lei Maria da Penha.A análise foi realizada a partir de uma atividade de extensão com objetivo de desnaturalizar a violência doméstica e difundir os instrumentos jurídicos da Lei Maria da Penha a partir de encontros interativos com as mulheres participantes dos Clubes de Mães da Associação Feminina de Assistência Social de Criciúma/SC (AFASC), da qual emergiu importantes relatos. O resultado foi a percepção de que muitas mulheres se encontram na situação descrita e não têm perspectiva de melhora. Concluiu-se que a crescente crise e a misoginia na sociedade impedema saída da mulher, vítima de violência, do lar do agressor, tornando-a ainda mais oprimida.

Palavras-chave: Extensão universitária. Violência doméstica. Trabalho. Renda.

\section{RESUMEN}

Este trabajo tiene como objetivo analizar La violencia doméstica y las luchas de lãs mujeres para prevenir y combatir La violencia, a lo largo de los años, dicho análisis denota una serie de factores, y entre ellos se pretende estudiar La violencia patrimonial, por ejemplo, enumerada enel artículo 7, inciso IV de laLey Maria de Penha. El análisis se realizó a partir de una actividad de extensiónconel objetivo de desnaturalizar laviolencia doméstica y difundir los instrumentos legales de laLey Maria de Penha a través de encuentros interactivos con lãs mujeres participantes de los Clubes de Madres de La Asociación de Asistencia Social de Mujeres de Criciúma / SC de donde surgieron informes importantes. El resultado fue La percepción de que muchas mujeres se encuentran en La situación descrita y no tienen perspectivas de mejora. Se concluyó que La crisis creciente y la misoginia de lãs o ciedadimpiden que lãs mujeres, víctimas de La violencia, abandonen e lho garde La gresor, oprimiéndo La aún más.

Palavras clave: extensión universitária; violência doméstica; trabajo; renta.

\footnotetext{
${ }^{1}$ Curso de Direito da Universidade do Extremo Sul Catarinense, Criciúma, SC - Brasil. E-mail: lidiapugioni@unesc.net

2 Curso de Medicina da Universidade do Extremo Sul Catarinense, Criciúma, SC - Brasil

3 Integrantes do Projeto Amora da Universidade Do Extremo Sul Catarinense, Criciúma, SC - Brasil.
} 


\section{INTRODUÇÃO}

A palavra universidade, advinda do latim universitasdiz respeito a uma universalidade e nos remete a um conjunto, um todo. A universidade se estrutura em um tripé universitário, baseado na obrigação de ensino, pesquisa e extensão.

Segundo a Lei de Diretrizes e Bases da Educação (LDB, Lei n 9.394, de 20 de dezembro de 1996), o ensino superior deve devolver, além do ensino e da pesquisa, atividades de extensão respeitando requisitos estabelecidos em cada instituição. Conforme cita Freire (1969) em sua obra "Extensão ou Comunicação", "o conhecimento não se estende do que se julga sabedor até aqueles que se julga não saberem; o conhecimento se constitui nas relações homem-mundo, relações de transformação, eaperfeiçoa-se na problematização crítica dessas relações." Em outras palavras, ao nos aprofundarmos em estudos sobre a extensão universitária, primordialmente, devemos entender que não há superioridade entre aqueles que obtém o conhecimento técnico e os que o obtenham de forma manualno aprendizado prático.

Assim, a capacitação não ocorrerá de forma a transferir ou depositar termos técnicos, conforme Freire (1969), mas, muito pelo contrário, é o ato em que o técnico se oferece ao educando como um problema que este deverá responder. $\mathrm{O}$ atuar dos extensionistas, conforme cita Freire (1969) na mesma obra, "não se faz mediante um trabalho em nível puramente intelectualista, mas sim na práxis verdadeira, que demanda a ação constante sobre a realidade e a reflexão sobre esta ação. Que implica um pensar e um atuar corretamente”.

Nesse sentido, o Projeto Amora vem trabalhando desde 2011 com mulheres, por meio de encontros em órgãos como os Centros de Referência de Assistência Social (CRAS) e outras instituições que compõe a rede de atendimento às mulheres em situação de violência. Atualmente, o projeto ocorre junto aos Clubes de Mães da Associação Feminina de Assistência Social de Criciúma/SC (AFASC), compartilhando conhecimentos com as mulheres participantes dos 140 clubes cadastrados. O principal objetivo é difundir os instrumentos jurídicos da Lei Maria da Penha (Lei $n^{\circ}$ 11.340/06) para as mulheres do município de Criciúma-SC para promover o processo de desnaturalização da violência doméstica e familiar.

Sabe-se que há os fatores internos que se agregam ao contexto de violência domésticofamiliar, os quais integram desde a pressão em que a sociedade patriarcal,na qual estamos inseridos,exerce sobre a vítima e que a faz carregar a culpa pela violência sofrida, até o afeto que a vítima sente, muitas vezes, pelo seu agressor. Tal fato acaba gerando incerteza na vítima em relação ao fato de denunciar ou não a violência sofrida (PASINATO, 2012; JUBB, 2010). 
Nesse sentido, este artigo tem como foco principal as relações de violência propagadas entre maridos e mulheres, abordando uma problemática trazida por meio do artigo $7^{\circ}$, inciso IV, da Lei Maria da Penha, que trata da violência patrimonial.Para alcançar esse objetivo, o Projeto Amora em suas visitas aos Clubes de Mães ouviu e trocou conhecimento com inúmeras mulheres durante os vinte encontros propostos e concretizados no ano de 2019, entre o período dos meses de setembro a novembro.

Com base nesses relatos escutados pelas bolsistas e voluntárias do projeto, foi notório que, apesar dos avanços, a lei ainda se mostra obscura em alguns pontos, e que dos inúmeros fatores impeditivos da vítima abandonar a convivência com o agressor, um dos casos apontados e que gerou o interesse cientifico foi o de,por não haverem renda fixa laboral no âmbito público, as mulheres vítimas de violência doméstica não se sentem confortáveis para saírem do lar do agressor, preferindo, muitas vezes, sofrer a sair do local e/ou perecer por falta de sustento.

A metodologia utilizada neste projeto foi a análise teórica qualitativa com base nos relatos de extensão.

\section{PROCEDIMENTOS METODOLÓGICOS}

A experiência do Projeto Amora de extensão consistiu em atividades de visitas aos clubes de mães da AFASC (Associação Feminina de Assistência Social de Criciúma), dos 134 bairros da cidade de Criciúma - SC, durante o período do dia 03 de setembro do ano de 2019 até o dia 14 do mês de novembro de 2019.

Estas atividades eram desenvolvidas pelas professoras extensionistas responsáveis pelo projeto e pelas alunas do curso de Direito, bem como contava com a participação das alunas voluntárias do projeto, sendo uma aluna do curso de Direito e duas alunas do curso de Medicina, da própria instituição.

As atividades realizadas nos Clubes de Mães consistiam em rodas de conversa, onde, no local onde se realizavam os encontros semanais das integrantes com a monitora.

As bolsistas e as voluntárias iam até o local e, por cerca de 1 (uma) hora e meia, era realizada uma conversa acerca das nuances da Lei 13.340/2006, Lei Maria da Penha, fazendo um processo de desnaturalização da violência doméstica, bem como, dos tipos de violência constados na lei. Além disso, eram informados os números de contato de apoio nos casos de violência. 
As atividades eram realizadas duas vezes por semana, sendo seguido uma tabela com os 140 (cento e quarenta) clubes de mães do município de Criciúma - SC disponibilizada pela coordenadora geral da instituição, sendo que, após uma reunião mensal, eram definidos onde seriam os locais que seriam visitados.

As atividades foram pensadas para as mulheres participantes dos clubes de mães, - as quais se encaixavam na faixa etária de 18 (dezoito) a 60 (sessenta) anos e representavam diferentes classes econômicas e raças - a fim de alertá-las quanto ao perigo que a violência traz e de proporcionar incentivo para que elas conscientizem, também, outras mulheres a sua volta.

Nestas visitas, além da roda de conversa, eram utilizadas atividades antes e depois de serem explicados os temas, com o intuito de averiguar o que elas concebiam como violência, e como seria a sua visão após a conversa. Para as atividades foram utilizados materiais como um dado, confeccionado pelas próprias integrantes do projeto, onde em cada face havia um

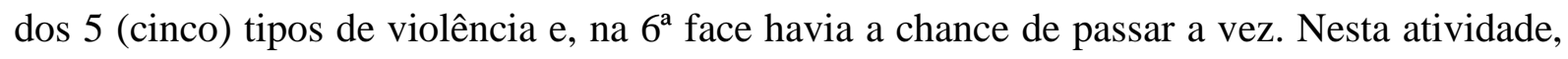
uma das integrantes do projeto jogava o dado e, ao anunciar o tipo de violência, uma das mulheres do clube que se sentisse à vontade, poderia explicar o que entendia quando se tratava daquele tipo de violência. Após a conversa, eram feitas perguntas a mulheres para ver o que pensavam após todas as informações compartilhadas.

Outra técnica utilizada, era a realização de uma brincadeira semelhante a "batata quente", na qual, uma das integrantes do projeto pegava uma caixa pequena e enfeitada e passava para elas, orientando que a mulher que ficasse com a caixa parada deveria obedecer ao comando escrito no papel que se encontrava dentro da própria caixa. Assim, com este mistério nas mãos, percebia-se a tensão delas em passar a "bomba" e não ficar com o encargo. Mas ao parar a brincadeira e abrir a caixinha, havia lá dentro um doce com os dizeres de "podes comer agora!". Nesta parte da brincadeira, explicávamos a didática comparando-a com a denúncia de violência, na qual as mulheres se sentiam acuadas de denunciarem por medo do que poderia vir a seguir, mas acabava por vir uma surpresa doce e boa, de forma a melhorar a sua vida.

Nas atividades era conversado também a respeito de como realizar a denúncias após sofrer uma violência doméstica, bem como abordados temas sobre como a violência psicológica, por exemplo, poderia acarretar em depressão, ou ainda, quem poderia praticar a violência, desconstituindo o imaginário popular de que somente o marido poderia cometer tal violência. Sendo assim, considerou-se uma forma produtiva de espalhar o conhecimento técnico a comunidade de uma forma precisa. 


\section{ANÁLISE HISTÓRICA-SOCIAL}

Ao se analisar a violência de gênero nos dias atuais, muito se discute a respeito de suas origens e, principalmente, a forma como o tema evoluiu e chegou à problemática atual. Conforme uma reportagem no site Folha de São Paulo,o Ministério da Saúde, em 2019, informou que, em nosso país,a cada quatro minutos, uma mulher é agredida por pelo menos um homem e sobrevive. Na mesma matériasão apresentados mais dados assustadores a respeito do problema: apenas no ano de 2018foram registrados mais de 145 mil casos de violência. ${ }^{2}$ É inegável que ao analisar os dados que são divulgados, percebemos o aumento de denúnciasde agressões sofridas dentro do lar, por meio de atitudes, palavras de pessoas de convivência costumeira.

A violência à mulher é um tema que vem sido bastante discutido ao longo dos anos, principalmente após a promulgação da Lei Maria da Penha (Lei 11.340/2006), que visa proporcionar instrumentos a fim de coibir, prevenir e erradicar o problema de saúde pública que é a violência de gênero. Entretanto, muito tempo antes de ser promulgada, além de tratados e convenções internacionais, como a Convenção sobre a eliminação de todas as formas de discriminação contra as mulheres (CEDAW - 1979), a violência se perpetua, conjuntamente com o machismo e com a misoginia que são, infelizmente, ensinados em nossa sociedade.O intuito deste trabalho é, por meio da metodologia de análise teórica qualitativa, analisar os relatos de extensão das bolsistas, em especial os depoimentos das participantes dos Clubes de Mães da AFASC, em que relatam a dificuldade em que muitas mulheres passam ao denunciar a violência doméstica e sair do lar do agressor, nesse contexto em específico o marido.Para ser compreendido este fenômeno, é importante lembrar o legadocultural da mulher na história. Primitivamente, a mulher exercia funções sociais como as dos homens, uma vez que,enquanto esses saiam para a caça e pesca, as mulheres desempenhavam as atividades agrícolas e as tarefas domésticas, sendo as comunidades primitivas desprovidas de matérias jurídicas, prevalecendo o direito repressivo (Tabosa, 2005). Com a evolução do que mais tarde foi conceituado como sociedade, e com as suas nuances e complexidades, o direito como efeito de mudanças foi acompanhando esta caminhada.

Entretanto, quando se trata do gênero feminino, esse desenvolvimento caminha a passos lentos, já que ocorre aumento da riqueza individual do homem, monopolização política

\footnotetext{
${ }^{2}$ Dados obtidos pelo site Folha de São Paulo por meio do Sinan (Sistema de Informação de Agravos de Notificação), obtidos pelo site por meio da Lei de Acesso à Informação. A reportagem analisou 1,4 milhões de notificações dos anos de 2014 a 2018.
} 


\section{UGIONI; SCHWANCK}

e queda do direito materno, gerando uma enorme desigualdade jurídico-social entre homens e mulheres que. O Direito Romano, por exemplo, desprovia a mulher de capacidade jurídica, fazia com que a mulher solteira vivesse sob o pátrio poder do pai e a casada vivesse sob o poder do marido (Tabosa, 2003).Nota-se que, ao haver uma classificação entre os gêneros masculino e feminino, há uma assimetria, onde o grupo feminino é subjugado. De forma a exemplificar, na Grécia os mitos relatavam que por sua imensa curiosidade, advinda do sexo feminino, Pandora tinha aberto a caixa de todos os males do mundo, e por isso, todas as mulheres eram responsáveis pelas desgraçadas desencadeadas ao mundo em que vivemos. Cabe ressaltar aqui que muitas das grandes religiões justificam ao longo dos tempos as condutas dos sexos. (PULEO, 2004, p. 13)

As primeiras sociedades, descritas nos estudos históricos como pioneiras em assuntos como cidadania e debates, tinham muitas diferenças entre os gêneros masculino e feminino. Na sociedade, as mulheres não gozavam de direitos jurídicos, não recebiam educação formal, muito menos eram permitidas de saírem em público, devendo estas ser confinadas em suas próprias casas, conforme diz Gineceu. Do contrário a esta situação imputada às mulheres, era a vida do homem, que era um polígamo e soberano mediante a sociedade patriarcal, que pode, inclusive, ser descrita como 'clube masculino mais exclusivista de todos os tempos', tendo, além de direitos civis e políticos plenos, poder absoluto sobre as mulheres (VRISSIMTZIS, 2002, p. 38).

Já em Roma, “elas nunca foram consideradas cidadãs e, portanto, não podiam exercer cargos públicos” (FUNARI, 2002). A exclusão social, jurídica e política imputada a estas mulheres, colocavam-nas no mesmo patamar das crianças e dos escravos, sendo que aquelas tinham como função social ser a procriadora.

Ao começar a difundirem a religião judaico-cristãpouco se alterou esta situação, haja vista que o cristianismo retratava as mulheres como pecadoras e culpadas pelo desterro dos homens do paraíso, desde que Eva mordeu "o fruto proibido". As mulheres, em suma deviam, portanto, seguir a trindade da obediência, passividade e submissão aos homens, estes seres de grande iluminação e capazes de dominar as mulheres, com seus instintos animalescos e irrefreáveis, levando-as para a salvação.

Não só a religião fazia um papel de normatização do sexo feminino, mas a medicina também vinha fazendo este papel, quando até meados do século XVI, pregava a existência de um corpo canônico, o masculino. Para estes, a vagina era tratada como um pênis interno, criando a crença de que a mulher seria um homem invertido e, por este motivo, um ser 
inferior, conforme se identifica nos registros em que Laqueur (2001) comenta a visão de Aristóteles:

\begin{abstract}
O kurios, a força do esperma para gerar uma nova vida, era o aspecto corpóreo microcósmico da força deliberativa do cidadão, do seu poder racional superior e do seudireito de governar. O esperma, em outras palavras, era como que a essência do cidadão. Por outro lado, Aristóteles usava o adjetivo akuros para descrever a falta de autoridade política, ou legitimidade, e a falta de capacidade biológica, incapacidade quepara ele definia a mulher. Ela era, como o menino, em termos políticos e biológicosuma versão impotente do homem, um arrenagonos. (LAQUEUR, 2001).
\end{abstract}

Essa visão androcêntrica perdurou por muitos anos, afirmando ser a mulher uma categoria vazia. Apenas após anos de luta e depois de a mulher configurar-se na vida política, econômica e cultural, é que houve uma necessidade de serem diferenciados os gêneros de forma anatômica e fisiológica.

O eixo naturalista, imposto em boa parte do século XVIII, começou a ser desconstruído neste mesmo século com o início da Revolução Francesa (1789), que contou com a participação ativa de mulheres que acreditavam nos ideais de igualdade, fraternidade e liberdade, os quais deveriam ser estendidos a sua categoria.

Nota-se, contudo, que não houve tais benesses a ambos os sexos, criando-se então um movimento de mulheres que reivindicavam seus ideais não contemplados. Um exemplo destas mulheres foi Olympe de Gouges, um pseudônimo para Marie Gouze, uma dramaturga, ativista política, feminista e abolicionista francesa, que defendeu a democracia e o direito das mulheres. Gouges publicou em 1791 um texto intitulado Os Direitos da Mulher e da Cidadã, onde levanta a seguinte questão:

\footnotetext{
Diga-me, quem te deu o direito soberano de oprimir o meu sexo? [...] Ele quer comandar como déspota sobre um sexo que recebeu todas as faculdades intelectuais. [...] Esta Revolução só se realizará quando todas as mulheres tiverem consciência do seu destino deplorável e dos direitos que elas perderam na sociedade. (ALVES, \& PITANGUY, 1985, p. 33-34)
}

Já no século XIX, confere-se a consolidação do sistema capitalista que efetuou severas mudanças. $\mathrm{O}$ modo de produção criado afetou o trabalho femininolevando muitas mulheres às fábricas, ou seja, a mulher sai do espaço privado e vai à esfera pública. Neste cenário, iniciase a trajetória do movimento feminista, que pode ser definido como uma preocupação de erradicar discriminações sociais, econômicas, políticas e culturais em que a mulher figura como vítima (GREGORI, 1993, p. 15). 
Não obstante, pode-se fazer uma breve análise da história de opressão e violências em nosso paísonde, desde o período de Brasil Colônia, havia diferenciação entre a educação feminina e masculina que era oferecida pela Igreja Católica, que, dominante e absoluta,foi pioneira na educação, mas excluiu as mulheres de tal processo.

Diante da superioridade masculina vigente na época,observa-se um problema, como supracitado no início deste trabalho,que é a violência doméstica. O que se observa e acaba por criar, muitas vezes, uma padronização entre as vítimas de violência doméstica, são fatores internos de subordinação sendo incluído entre estes a falta de uma fonte de proventos em que garanta que essa mulher possa sair do seio familiar do agressor sem prejuízo a sua vida financeira e sustento próprio.

Em razão desse fator interno de subordinação, muitas mulheres não encontram a força necessária em fazer a denúncia e se afastar efetivamente do lar onde convivem com o agressor, haja vista não possuírem estabilidade financeira para prover seu próprio sustento edos seus dependentes que são menores incapazes.

\section{VIOLÊNCIA CONTRA A MULHER NOS DIAS ATUAIS}

Antes de mais nada, para se compreender a relação de trabalho e dinheiro, sendo estes motivos de desincentivo a denúncia por parte da ofendida,é importante que se faça uma análise histórica sobre o papel do feminismo no combate à violência doméstica, perpassando pelas convenções feitas em âmbito nacional e internacional, culminando na criação da Lei Maria da Penha (Lei 11.340/2006) para, por fim, entender como os fatores supracitados dificultam a mulher na denúncia do agressor e de abandonar o lar do mesmo.

Ao pesquisar a palavra feminismo no site de pesquisaGoogle, encontra-se aproximadamente26.300.000 resultados. Esse termo foi escolhido como a palavra mais pesquisadade 2017 pelo dicionário americano Merriam-Webster e a busca pelo termo cresceu em $200 \%$ desde $2016 .^{3}$

Na década de 1960, uma série de Convenções Internacionais, no âmbito da Organização das Nações Unidas (ONU) foram criadas, entre elas estão o Pacto Internacional de Direitos Civis e Políticos (1966, ratificado pelo Brasil em 1992), o Pacto Internacional de Direitos Econômicos, Sociais e Culturais (1966, ratificado pelo Brasil em 1992), bem como a Convenção Americana sobre os Direitos Humanos - Pacto de São José da Costa Rica (1969, ratificada pelo Brasil em 1992).

\footnotetext{
${ }^{3}$ Dados retirados do site da revista ISTOÉ. 
Todavia, o primeiro documento internacional voltado à proteção das mulheres é a Convenção sobre a Eliminação de Todas as Formas de Discriminação Contra a Mulher (em inglês, ConventionontheEliminationofallFormsofDiscriminationagainstWomen - CEDAW), que foi aprovada pela Assembleia Geral das Nações Unidas em 1979, e assinada pelo Brasil em 1984, com reservas, estas mantidas pelo Congresso Nacional. Após a Constituição de 1988, foram retiradas as reservas, e o Estado do Brasil concordou plenamente com a convenção no ano de 1994.

No artigo $7^{\circ}$ da Convenção Interamericana para Prevenir, Punir e Erradicar a Violência Contra a Mulher, ou Convenção de Belém do Pará, os Estados Partes concordaram em "velar para que as autoridades, seus funcionários, pessoal e agentes e instituições públicas" se comportem conforme a sua obrigação de abster-se de qualquer ação ou prática de violência contra a mulher e de que estes adotariam políticas orientadas a prevenir, a punir e a erradicar tais violências.

Conforme Streck e Lima (2014), os direitos fundamentais das mulheres seriam inseridos numa categoria de "tr(i)unfo", cuja ideia inspiradora remonta às lições de Dworkin, ${ }^{4}$ voltada aos direitos fundamentais individuais. De outro lado, esta concepção possui maior abrangência, em consideração a evolução da teoria dos direitos fundamentais, considerando suas múltiplas dimensões e gerações.

Ainda, segundo os autores, a concepção de trunfo tem reflexo na positivação da Lei Maria da Penha, em face da condenação do Estado Brasileiro por violação aos direitos humanos no caso da brasileira Maria da Penha Maia Fernandes. As inovações trazidas pelo referido diploma legal, podem ser elencadas da seguinte forma: 1) Mudança de paradigma no enfrentamento da violência contra a mulher;2)Incorporação da perspectiva de gênero para tratar da violência contra a mulher; 3)Incorporação da ótica preventiva, integrada e multidisciplinar; 4) Fortalecimento da ótica repressiva; 5) Harmonização com a Convenção Interamericana para Prevenir, Punir e Erradicar a Violência contra a Mulher de Belém do Pará; 6) Consolidação de um conceito ampliado de família e visibilidade do direito à livre orientação sexual; e 7) Estímulo à criação de bancos de dados e estatísticas.

\footnotetext{
${ }^{4}$ De acordo com Streck e Lima (2014, p. 342, apud DWORKIN, 2002) “Os direitos individuais são trunfos políticos que os indivíduos detêm. Os indivíduos têm direitos quando, por alguma razão, um objetivo comum não configura uma justificativa suficiente para negar-lhes aquilo que, enquanto indivíduos, desejam ter ou fazer, ou quando não há uma justificativa suficiente para lhes impor alguma perda ou dano". Cf. DWORKIN, Ronald. Levando os direitos a sério. Trad. Nelson Boeira. São Paulo: Martin Fontes, 2002. Introdução, XV.
} 
Conquanto esta lei viesse para amparar as mulheres, ainda assim os dados apontam que a violência perdura e, em muitos casos, esta não é denunciada. Muitas das mulheres em situação de violência acabam caindo no conceito que a criminologia chama de "cifra oculta da criminalidade", termo traduzido do inglês "Dark figure of crime".

Nas palavras de Araújo Júnior (1996, p. 245), "Denomina-se 'cifranegra', chiffrenoir oudarknumberda criminalidade, adiferença entreonúmerototalde crimes cometidos em um determinado período ea criminalidade oficialmente detectada através dasestatísticaspoliciais e judiciais". Portanto, é notórioentender que entre o acontecer do fato criminoso e o registro que venha a se tornar estatística, muito se depreende nesse meio tempo, submetendo-sea ações transformadoras com múltiplas vicissitudes e que convertem o chamado 'crime real' em um ‘crime estatístico’ (DIAS E ANDRADE, 1984, p. 132-3).

Assim, ao entendermos o conceito de cifra oculta da criminalidade, podemos associar e explicar como muitos de nós ouvimos diversos casos de mulheres em situações de violência, e ainda assim, as estatísticas oficiais não apresentam dados compatíveis a isso. Um dos fatores que levam a não denúncia ou a desistência dessa é o fator de renda. Apesar de a mulher ter saído para trabalhar após o início da Revolução Industrial, o caminho ainda é árduo para o gênero na vida laboral. De acordo com SOUSA E GUEDES (2016, p. 1):

Com as transformações no cenário socioeconômico, com as revoluções culturais e a força do movimento feminista no século XX, novas configurações sociais foram surgindo, fragilizando de modo conjunto a dicotomia entre público e privado e o modelo homem provedor e mulher cuidadora.

Esta saída da mulher do lar em tempo integral, porém, não fez com que ela perdesse o cargo de 'do lar', muitas vezes, fazendodupla jornada de trabalho, na qual, além de ter uma atividade laboral pública, ainda lhe é relegado os afazeres domésticos de forma massivasem ajuda do cônjuge ou companheiro, ficando a seu encargo a limpeza da casa, alimentação e até mesmo educação dos filhos. Para Hirata e Kergoat (2007), a divisão sexual do trabalho é fruto da divisão social estabelecida nas relações sociais entre os sexos, divisão essa modulada histórica e socialmente e instrumento da sobrevivência da relação social entre os sexos.

Frequentemente, ouvem-se relatos de mulheres de idades avançadas, que viveram sua juventude entre os anos 40 e 80, em que estas contam as dificuldades que ensejava o não abandono do lar em situações de violência doméstica. Estas dizem que, ao sair de casa para o matrimonio, não lhes era dada a chance de voltar para o lar dos pais, no caso de ser agredida pelo marido ou de o casamento não funcionar. Caso desejasse pedir o divórcio, seria rejeitada 
não tão somente pelos familiares, mas seria escrachada pela sociedade patriarcal, muito mais forte em tempos passados. Ocorre, erroneamente, em pensarmos que os tempos evoluíram, entretanto, caminhamos a passos lentos.

Em uma pesquisa no Google sobre a relação mulheres x emprego, encontramos diversas matérias, entre as quais pode-se concluir que mulheres ganham menos que os homens e, na atual crise, estas são as que mais têm dificuldades em achar emprego fixo e com carteira assinada. Em consulta ao site Brasil de Fato,em uma matéria publicada ao Dia Internacional da Mulher, contatou-se que, de acordo com dados da Pesquisa Nacional por Amostra de Domicílios Contínua (Pnad Contínua), realizada pelo Instituto Brasileiro de Geografia e Estatística (IBGE), a informalidade atingiu 41,1\% da população brasileira no quarto trimestre de 2019, sendo o maior nível desde 2016. Ainda com a criação das vagas informais, cresce o número de desemprego, principalmente no gênero feminino, onde a taxa de desocupação total entre mulheres no quarto trimestre de 2019 chegou a 13,1\%, enquanto a do gênero masculino o índice alcançava a 9,2\%.

Indubitavelmente, mulheres em situação de violência sofrem mais para achar uma vaga de emprego formal, considerando toda a bagagem que as envolvem, o fato de desejarem sair do lar de convivência do agressor, bem como a necessidade de cuidar dos filhos, além da pressão psicológica da sociedade em ser uma mãe solteira após a separação do marido. Esta situação encontra-se no ciclo da violência no qual, muitas vezes, na fase de perdão ou a chamada lua de mel, o agressor faz uso de chantagens psicológicas em que a ofendida acaba por desistir de denunciar, afinal, após ser abusada psicologicamente, a mulher pensa que nunca será capaz de sustentar a si mesma e, eventualmente, um menor dependente.

\section{RESULTADOS E ANÁLISES}

Após as atividades em comunidade, com a experiência das bolsistas e voluntárias e com base no olhar crítico sobre o que viam pessoalmente, foram feitos relatórios para análises internas tanto das alunas do projeto quanto das professoras extensionistas. Pelos relatos das mulheres, percebeu-se que um dos objetivos do projeto foraconcluído, o qual propunha-se a conversar de maneira acessível com mulheres, principalmente, de idades mais avançadas e experientes, e perceber sua visão de mundo a partir do tema da violência.

Em muitos dos encontros, após a explicação do tema e realização das brincadeiras, ouviram-se relatos de mulheres que sofriam violências de ex-companheiros, ou histórias de amigas próximas das mulheres do clube de mães que relatavam também ter sofrido violências 
parecidas. O impacto do projeto apresenta-se de forma positiva, já que muitas mulheres absorveram o conhecimento e entenderam o que lhes foi explicado ao longo dos encontros, muitas vezes até mencionando que repassariam tais informações às suas amigas, filhas e até netas, o que em suma também foi um dos objetivosdesta ação do projeto.

Os relatos, que deram origem ao tema deste trabalho, estavam presentes em muitos dos clubes de mães, consistindo em situações que as mulheres viveram uma experiência de violência doméstica e, ao pensarem em abandonar o lar do agressor, simplesmente viam-se impossibilitadas, devido ao fato de que seriam rejeitadas pela família e pela sociedade. Além disso, era muito presente nas falas das mulheres o fato de que, mesmo nos dias atuais, parentes mais jovens de suas famílias relatavam a elas não saírem do lar do agressor tanto por acreditarem na mudança do companheiro, quanto por não se proverem financeiramente e/ou nãoconseguirem tal sustento tão brevemente.

Nos relatos das monitoras dos clubes de mães, após ter finalizado as reuniões com as mulheres participantes, muitas afirmaram que houve resultados positivos entre as integrantes, uma vez que, fora dos clubes de mães, as mulheres ainda falavam sobre o que era conversado no projeto Amora, citando que os conhecimentos adquiridos foram também repassados às suas famíliascomo forma de prevenção da violência.

\section{CONSIDERAÇÕES FINAIS}

O Projeto Amora tem uma trajetória de aproximadamente 10 anos de experiência em conversas com mulheres sobre seus direitos humanos. O grupo que visitou os Clubes de Mães da Associação Feminina de Assistência Social de Criciúma/SC (AFASC) iniciou sua jornada em setembro de 2019 e finalizou em novembro de 2019, conversando sobre violência contra a mulher e absorvendo novos conhecimentos acerca do tema.

Destaca-semuito pontos positivos em relação ao projeto, como a ideia central de levar o conhecimento acadêmico a mulheres quenão tinham acesso a tal. Outro ponto importante a ser ressaltado são os relatos das mulheres, nos quaisalegam já terem sofrido algum dos tipos de violências positivadas no corpo da leiou, também, conhecerem alguma mulher que tenha sofrido tais violações dos seus direitos.

Como já citado muitasmulheres relataram a dificuldade em saírem do lar do agressor em virtude de condições econômicas, as quais as impedem de colocar um fim neste sofrimento, dada a falta de uma renda que possa prover uma vida de paz, longe de agressões e ameaças. Infere-se que, a experiência do projeto contribui, de forma positiva, às acadêmicas e 
professoras que acabam adquirindo mais conhecimento e experiências ao saírem dos clubes em comparação ao período de início do projeto.

O benefício do projeto para as mulheres que entram na roda de conversa, é o fato de que elas acabam compreendendo as nuances da lei, bem como a forma de atendimento da rede, que se propõe a ouvir e auxiliar mulheres em situação de violência no município de Criciúma/SC.

\section{AGRADECIMENTOS}

Antes de mais nada, há de se agradecer ao projeto, e todas as pessoas que nele estão envolvidas, pois cada uma, de forma singular, faz este projeto ser conhecido do jeito que é, de uma forma carinhosa, sempre relembrado por onde passa. O Projeto Amora faz um trabalho lindo tanto dentro da Universidade, entre as orientadoras, as bolsistas e as voluntárias, quanto fora dela, com o cuidado e o carinho que propaga às mulheres dos clubes de mães.

Agradecer também à coordenação do curso de Direito, por permitir a continuidade desse trabalho que vem mudando a experiência cidadã, não só das alunas integrantes do Amora, como também da sociedade, ambos com a oportunidade de efetuar uma mudança na forma como se vê a violência de gênero.

\section{FONTE FINANCIADORA}

Edital PROFEDIR 2019.

\section{REFERÊNCIAS}

BARATTA, Alessandro. Criminologia Crítica e Crítica do Direito Penal: Introdução à Sociologia do Direito Penal. Rio de Janeiro, 2002. 256 p.

ARAÚJO JÚNIOR, João Marcello de. Vitimação entre estudantes de Direito da UERJ: um estudo de criminografia (violência e criminalidade tríplice violação da cidadania)". In Revista Brasileira de Ciências Criminais. Vol. 16, São Paulo: out./dez. 1996, p. 238251.

BRANDALISE, Camila; CAVICCHIOLI, Giorgia.Revolução Feminista. ISTOÉ. 2018. Disponível em: https://istoe.com.br/revolucao-feminista/.Acesso em 30. jun. 2020.

Convenção sobre a Eliminação de Todas as Formas de Discriminação contra a mulher (CEDAW). Disponível em: www.onumulheres.org.br/wpcontent/uploads/2013/03/convencao_cedaw.pdf . Acesso em 27 out. 2020.

FREIRE, P. (1983). Extensao ou Comunicaçao? (Tradução de RosiscaDarcu de Oliveira). $7^{\text {a }}$ ed. (1 ${ }^{\text {a }}$ edición:1969). Rio de Janeiro: Paz e Terra. 
GREGORI, M. F. Cenas e queixas: um estudo sobre mulheres, relações violentas e a prática feminista. 1. ed. Rio de Janeiro: Paz e Terra; São Paulo: ANPOCS, 1993.

HIRATA, Helena; KERGOAT, Danièle. Novas configurações da divisão sexual do trabalho. Cad. Pesqui., São Paulo, v. 37, n. 132, p. 595-609, Dez, 2007. Disponível em: www.scielo.br/scielo.php?script=sci_arttext\&pid=S0100$15742007000300005 \& \operatorname{lng}=$ en\&nrm=iso. Acesso em 27 out. 2020.

LAQUEUR, Thomas Walter. Inventando o sexo: corpo e gênero dos gregos a Freud. Trad. Vera Whately. 1. ed. Rio de Janeiro: RelumeDumará, 2001.

PULEO, Alicia. Filosofia e gênero: da memória do passado ao projeto de futuro. In: GODINHO, Tatau; SILVEIRA, Maria Lúcia (Orgs.). Políticas públicas e igualdade de gênero. 1. ed. São Paulo: Coordenadoria Especial da Mulher, 2004. p.13.34.

Revista Brasileira de Ciências Criminais: RBCCrim, São Paulo, v. 22, n. 111, p. 333-357, nov./dez. 2014.

Revista Brasileira de Ciências Criminais: RBCCrim, São Paulo, v. 26, n. 146, p. 273-303, ago. 2018.

RUDNICKI, Dani.Acesso à Justiça Penal: Cifra oculta da criminalidade e defesa efetiva do acusado. Ministério Público do Estado de São Paulo. 2001. Disponível em:www.mpsp.mp.br/portal/page/portal/documentacao_e_divulgacao/doc_biblioteca/bibli_se rvicos_produtos/bibli_boletim/bibli_bol_2006/RDP_07_57.pdf. Acesso em 30. jun. 2020.

SOUSA, Luana Passos de; GUEDES, Dyeggo Rocha. A desigual divisão sexual do trabalho: um olhar sobre a última década. Estud. av., São Paulo, v. 30, n. 87, p. 123-139, Aug. 2016. Disponível em:www.scielo.br/scielo.php?script=sci_arttext\&pid=S010340142016000200123\&lng=en\&nrm=iso. Acesso em 05. jul. 2020.

SUDRÉ, Lu. A crise tem rosto de mulher: elas são as mais afetadas pelo desmonte dos direitos. Brasil de Fato. 2020. Disponível em: www.brasildefato.com.br/2020/03/08/a-crisetem-rosto-de-mulher-precarizacao-e-desmonte-de-politicas-afetam-mais-elas. Acesso em 05. jul. 20 .

ANDRADE, Vera Regina Pereira de. A ilusão de segurança jurídica: do controle da violência à violência do controle penal. Porto Alegre, 2015. 338 p.

VRISSIMTZIS, Nikos A. Amor, Sexo e Casamento na Grécia Antiga. Trad. Luiz Alberto Machado Cabral. 1. ed. São Paulo: Odysseus, 2002.

ZAREMBA, Júlia.; CUBAS, Marina Gama.; AMÂNCIO, Thiago.Brasil registra um caso de agressão a mulher a cada 4 minutos, mostra levantamento. Folha de São Paulo.

Disponível em: www1.folha.uol.com.br/cotidiano/2019/09/brasil-registra-1-caso-de-agressaoa-mulher-a-cada-4-minutos-mostra-levantamento.shtml. Acesso em 15. jun. 2020. 
MULHERES EM SITUAÇ̃̃O DE VIOLÊNCIA E O ÂMBITO PÚBLICO-LABORAL

COMO FORMA DE OPRESSÃO 